\title{
A transformação do processo de ensino e aprendizagem não é um voo de galinha
}

The transformation of the teaching and learning process is not a chicken flight

La transformación del proceso de enseñanza y aprendizaje no es un vuelo de gallina

\section{Manolita Correia Lima}

- Doutora em Educação pela Faculdade de Educação da Universidade de São Paulo (FE-USP)

- Mestre em Sociologia pela Universidade Paris 7 - Université Denis Diderot

- Graduada em Ciências Sociais pela Universidade Paris 3 - Sorbonne-Nouvelle

- Tem experiência docente em cursos de graduação e pós-graduação em Administração

- Coordenadora do Núcleo de Inovação Pedagógica da Escola Superior de Propaganda e Marketing (ESPM)

- E-mail: mclima@espm.br

\section{Claudia Cristiane dos Santos Silva}

- Doutoranda no Programa de Mestrado e Doutorado em Administração (PPGA) da ESPM

- Mestre em Gestão Internacional pela ESPM

- Graduada em Turismo pela Pontifícia Universidade Católica do Rio Grande do Sul (PUC-RS)

- Integrante da equipe do Núcleo de Inovações Pedagógicas da ESPM

- E-mail: claudia@espm.br

\section{Danilo Martins Torini}

- Mestre em Sociologia pela Universidade de São Paulo (USP)

- Pós-graduado em Pesquisa de Marketing, Opinião Pública e Mídia pela Escola de Sociologia e Política de São Paulo

- Professor no Laboratório de Aprendizagem e no Programa LifeLab ESPM

- Coordenador de Pesquisa do Núcleo de Inovação Pedagógica (NIP) da ESPM

- E-mail: danilo.torini@espm.br 


\section{Resumo}

Se a educação corresponde a um meio de integrar o indivíduo à sociedade da qual faz parte, até que ponto, na contemporaneidade, a educação formal tem colaborado para a formação de jovens capazes de viver os desafios decorrentes de sociedades intensivas de conhecimento, profundamente exigentes em aprendizagem, capazes de compreender, conceber e implantar transformações sustentáveis no mundo em que vivem? É à sistematização dos debates que partem dessa questão principal que se dedica este ensaio acadêmico, apoiado não apenas em contribuições da literatura, mas também em outros dois importantes aportes: os diálogos com estudantes de um programa de pósgraduação stricto senso em administração voltado à formação científica de pesquisadores e professores e o aprendizado decorrente do trabalho em andamento em um núcleo de inovação pedagógica de uma instituição de educação superior.

PALAVRAS-CHAVE: SOCIEDADE INTENSIVA DE CONHECIMENTO • INSTITUIÇÕES EDUCACIONAIS INTENSIVAS EM APRENDIZAGEM • NOVO PARADIGMA PEDAGÓGICO • FORMAÇÃO DE PROFESSORES UNIVERSITÁRIOS.

\section{Abstract}

If education is a means of integrating the individual to society, to what degree has contemporary formal education made a contribution to the education of young people who are able to meet the challenge of knowledge-intensive societies and are capable of conceiving, understanding and implementing sustainable transformations in the world where they live? The systematic alignment of the debate that emerges from this question is the principal purpose of this academic essay. This is supported not only by the bibliography but also by two important contributions, namely the dialogue with graduate students in a school of Business Administration who are being prepared for academic and research endeavors and the ongoing learning resulting from an educational innovation initiative at an institution of higher education.

\section{KEYWORDS: KNOWLEDGE-INTENSIVE SOCIETY • KNOWLEDGE-INTENSIVE EDUCATIONAL INSTITUTIONS • NEW} TEACHING PARADIGMS • DEVELOPMENT OF UNIVERSITY-LEVEL EDUCATORS.

\section{Resumen}

Si la educación corresponde a un medio de integrar el individuo a la sociedad de la cual es parte, ¿hasta que punto, en la contemporaneidad, la educación formal ha colaborado para la formación de jóvenes capaces de vivir los desafíos resultantes de las sociedades intensivas de conocimiento, exigentes en aprendizaje, capaces de comprender, concebir e implementar transformaciones sostenibles en el mundo en que viven? Es para sistematizar los debates que parten de este tema principal el objetivo de este ensayo académico, apoyado no solo por contribuciones de la literatura, sino también en dos otras contribuciones importantes: los diálogos con estudiantes de un programa de posgrado, stricto sensu en Administración dirigido a la formación científica de investigadores y docentes y el aprendizaje resultante del trabajo en curso en un centro de innovación pedagógica de una institución de educación superior. 
Um pássaro não voa dentro de água. Um peixe não nada em terra. Um professor não se forma nos atuais ambientes universitários, nem em ambientes escolares medíocres e desinteressantes (António Nóvoa, 2019)

0 s momentos marcados por grandes transformações requerem exercícios de reflexão acompanhados pela promoção de debates qualificados. Quando eles atingem o ambiente educacional, é fundamental que a reflexão envolva a comunidade acadêmica e antecipe a definição de políticas, programas e ações. Desenhar modelo ou prescrever soluções talvez não seja o ideal, uma vez que vivemos contextos muito diversos e isso costuma demandar soluções (no plural). Contudo, as solicitações decorrentes de uma agenda transbordante nos distanciam de exercícios reflexivos porque eles são exigentes em tempo e esforços. "Sem tempo para pensar, nenhuma acção é possível, apenas uma reacção, uma resposta instantânea, irreflectida" (NÓVOA, 2019, p.56). Isso tem justificado a "interdição do diálogo, da partilha, do encontro, da reflexão e, nesse sentido, temos, hoje, mais a informação do que o conhecimento" (BRAGANÇA, 2011, p.159). Na contramão desse movimento, nos últimos cinco anos (2015-2019) participamos de debates que aproximaram gestores e professores, não raro, estudantes da educação superior.

A natureza das questões inspiradoras dos referidos debates apresenta discreta variaçã e converge para preocupações mais gerais. Levando em conta que se aprende cada vez mais cedo, o tempo todo e em qualquer lugar, quais seriam as transformações que a educação formal precisa promover para continuar pertinente? Quais são as transformações que se fazem relevantes quando se necessita investir em instituições intensivas em aprendizagem? Quando vida e trabalho parecem cada vez mais inseparáveis, como as instituições educacionais podem colaborar para se imprimir uma relação virtuosa entre essas dimensões da existência humana? E, mais especificamente, quais são as mudanças que se processam nos projetos pedagógicos? Como preservar a pertinência dos espaços de "ensino"? À medida que os objetivos justificadores dos cursos se alteram - e isso influi sobre os desenhos curriculares e sobre o planejamento do ensino-aprendizagem, requerendo novas formas de ensinar e aprender -, como trabalhar para professores e estudantes assumirem novas responsabilidades?

Pormenorizando as preocupações que aproximam os debatedores, é possível identificar seis eixos de discussão: a) a educação que faz sentido para jovens que estarão ativos no século XXII; b) a instituição educacional que se faz necessária hoje; c) os saberes que merecem ser ensinados/aprendendidos, competências que necessitam ser desenvolvidas; d) o perfil de professores ajustados às exigências do ensino orientado pela aprendizagem; e) a mobilização de estudantes e professores para a aprendizagem; f) a ampliação / diversificação dos espaços de aprendizagem ${ }^{1}$. Eixos que estão em sintonia com a literatura: a título de exemplo, em 2012, Julien Gautier e Guillaume Vergne publicam L'école, le numérique et la société qui vient, livro em que o conteúdo consolida entrevistas com três intelectuais franceses - Denis Kambouchner (filósofo), Philippe Meirieu (educador) e Bernard Stiegler (filósofo) -, cuja provocação inicial reside em saber de quais escolas necessitamos atualmente? ("de quelles écoles avons-nous besoin aujourd'hui?") e quais saberes ensinar? ("quels savoirs enseigner..."?). Na mesma trilha, em 2018, Yuval Noah Harari assina um livro sugestivamente intitulado de 21 lições para o século 21 e chama atenção para o fato de que um jovem que ingressar na universidade em 2020 terá fortes chances de ser um cidadão ativo no século XXII e isso representa um convite para se refletir sobre o que ensinar e o que aprender contemporaneamente, sobre as habilidades de que os jovens precisam desenvolver para viver e sobre como viver em um mundo em que a profunda incerteza não é um bug, mas uma característica do momento.

As transformações no ambiente educacional são exigentes, complexas, caras e permanentes porque refletem rápidos e intensos processos de transformação que ocorrem na sociedade. Frente a um contexto marcado por importantes e aceleradas mudanças, quais são as consequências de a educação e respectivos atores sociais insistirem em permanecer indiferentes à necessidade de transformação? Se a educação corresponde a um meio de integrar o indivíduo à sociedade da qual faz parte, até que ponto, na contemporaneidade, a educação formal tem colaborado para a formação de jovens

\footnotetext{
1 Nesse contexto, aprendizagem corresponde a um "processo não linear, interpretativo, criativo, expressando principalmente conquistas de autoria e autonomia, individual e coletiva" (DEMO, 2011, p. -56).

2 No âmbito desse texto, a ideia de formação está alinhada à teoria tripolar da formação humana à medida que envolve três dimensões: autoformação é a dimensão pessoal de reencontro reflexivo em que as questões do presente nos levam a problematizar o passado e a construir projeto sobre o futuro; a heteroformação aponta para a significativa presença de muitos outros que atravessam nossa história de vida, pessoas com quem aprendemos e ensinamos; a ecoformação aborda nossa relação com o mundo, o trabalho e a cultura (PINEAU, 1988, apud BRAGANÇA, 2011).
} 
capazes de viver os desafios decorrentes de sociedades intensivas de conhecimento, profundamente exigentes em aprendizagem; capazes de compreender, conceber e implantar transformações sustentáveis no mundo em que vivem?

Com o ensaio acadêmico em tela, pretende-se sistematizar os debates em que participamos, sem desconsiderar as leituras realizadas e os diálogos com estudantes do stricto sensu de um programa de pós-graduação em administração que insiste em contribuir para a formação científica de pesquisadores e professores, além do aprendizado decorrente do trabalho em andamento em um núcleo de inovação pedagógica de uma instituição de educação superior multicampi. A arquitetura das ideias desenvolvidas no texto integra uma contextualização histórica do processo educacional dividida em três momentos: gênese, revoluções industrial e pós-industrial. Na trilha do que se espera da educação no contexto do século XXI, o texto privilegia a discussão sobre conhecimento e currículo, formação pedagógica do professor que exercerá a docência na educação superior e espaços de ensino-aprendizagem.

\section{GÊNESE E CARATERÍSTICAS DA EDUCAÇ̃̃o FORMAL}

Há mais de dez anos, Derek Keats e Philipp Schmidt (2007), da University of Witwatersrand, de Joanesburgo, utilizaram o termo Education 3.0 para expressar o potencial das tecnologias digitais para o processo de ensino-aprendizagem, à medida que percebiam o quanto elas favoreciam a aprendizagem personalizada e colaborativa, simultaneamente. Seis anos depois, Jim Gillis Lengel (2013), da University of New York, publicou o livro Education 3.0: steps to better schools, assumindo a tese de que a educação está intrinsecamente associada às sucessivas revoluções industriais, e para fins didáticos ele organiza o processo educacional em três momentos que intitula educação 1.0, 2.0 e 3.0, respectivamente.

Sabe-se que as instituições educacionais refletem as características de seu tempo. Assim sendo, em velocidades distintas, elas promovem transformações e ao mesmo tempo se transformam. Referindo-se particularmente à universidade, Denis Bédard e Jean-Pierre Béchard (2009, p. 29) afirmam que "l'université a en fait toujours été soumise, au cours des siècles, à des influences extérieures qui ont affecté ses missions, ses façons de faire, voire ses raisons d'être. Que ce soit a partir des exigences ecclésiastiques, politiques ou économiques". Fundamentados pela consulta à literatura, os autores asseguram que as transformações promovidas nos ambientes educacionais respondem às pressões exercidas pelas forças externas, particularmente pelo ambiente econômico. Nessa trilha, exemplificam o que afirmaram assegurando que "l'industrie et les millieux de travail exercent des pressions sur les établissements d'enseignements supérieur pour que les étudiants soient de mieux en mieux préparés aux exigences et aux défis du marché" (BÉDARD; BÉCHARD, 2009, p. 32).

No período anterior à Revolução Industrial, por exemplo, a população era predominantemente rural, as pessoas trabalhavam a terra, ao ar livre, fazendo uso de ferramentas que produziam manualmente. 0 tempo dedicado ao trabalho correspondia ao tempo necessário para gerar o próprio sustento. Havia pouca variação em termos de ocupação e uso de recursos tecnológicos, o processo de mudança era lento, a mobilidade social era praticamente inexistente. Trabalhavase em pequenos grupos, especialmente derivados do núcleo familiar, prevalecia um ambiente comunitário. Os jovens realizavam o trabalho da mesma maneira que seus pais, avós ou bisavós. Apesar da variação de idade, havia espaço de diálogo entre as diversas gerações. Essa breve descrição reúne características típicas do ambiente de trabalho 1.0 (LENGEL, 2013).

De que modo tais características repercutiram sobre a concepção de educação que prevaleceu nos países localizados na Europa ocidental? 0 acesso à educação formal era restrito a poucos, recorrentemente aos homens brancos, nobres e representantes da burocracia eclesiástica ou militar. A grande maioria dos jovens era orientada pelos parentes mais velhos e experientes, e com isso as ocupações se perpetuavam entre as gerações. Essa dualidade cristalizava as distancias sociais. As atividades escolares, por sua vez, incluíam pessoas de distintas idades; assim sendo, recorrentemente, pais e filhos vivenciavam a mesma experiência educacional, eram expostos aos mesmos métodos de ensino e a conteúdos semelhantes. Não havia um lugar dedicado às atividades de ensino, em geral os aprendentes formavam pequenos grupos e todos usavam as mesmas ferramentas. Jim Gillis Lengel (2013) nomeia essa experiência educativa de educação 1.0. 


\section{GÊNESE E CARATERÍSTICAS DA CONCEPÇÃO DE EDUCAÇÃO NA ERA INDUSTRIAL}

Com a emergência da Revolução Industrial, parte da população que vivia no meio rural migrou para as cidades (burgos) e houve expressiva alteração na organização do trabalho. Pelo fato de o trabalho ser organizado em linha de produção, sofreu uma espécie de esmigalhamento e com isso o trabalhador passou a realizar uma fração do processo de produção, consequentemente o trabalho perdeu grande parte de seu significado social (FRIEDMANN, 1972). 0 trabalhador se submeteu a rígida disciplina, para viabilizar a supervisão de homens e mulheres, crianças e adultos eram confinados em fábricas capazes de reunir expressivo contingente de operários, que, por sua vez, respeitavam uma grade horária, organizada em turnos. Sozinhos, em silêncio, enfileirados, cada um em uma máquina, os trabalhadores desenvolviam as mesmas atividades, fazendo uso de ferramentas mecânicas. A Revolução Industrial deixou como legado a teoria da linha de produção (HARARI, 2018). Em síntese, o trabalho industrial assumiu um caráter mecânico, repetitivo e isolado, características típicas do ambiente de trabalho 2.0 (LENGEL, 2013). De que modo tudo isso repercutiu sobre a concepção de educação que prevaleceu nessa época e que em alguma medida se estende aos dias atuais?

\section{Foto 1 - Trabalho fabril: organização do ambiente de trabalho.}

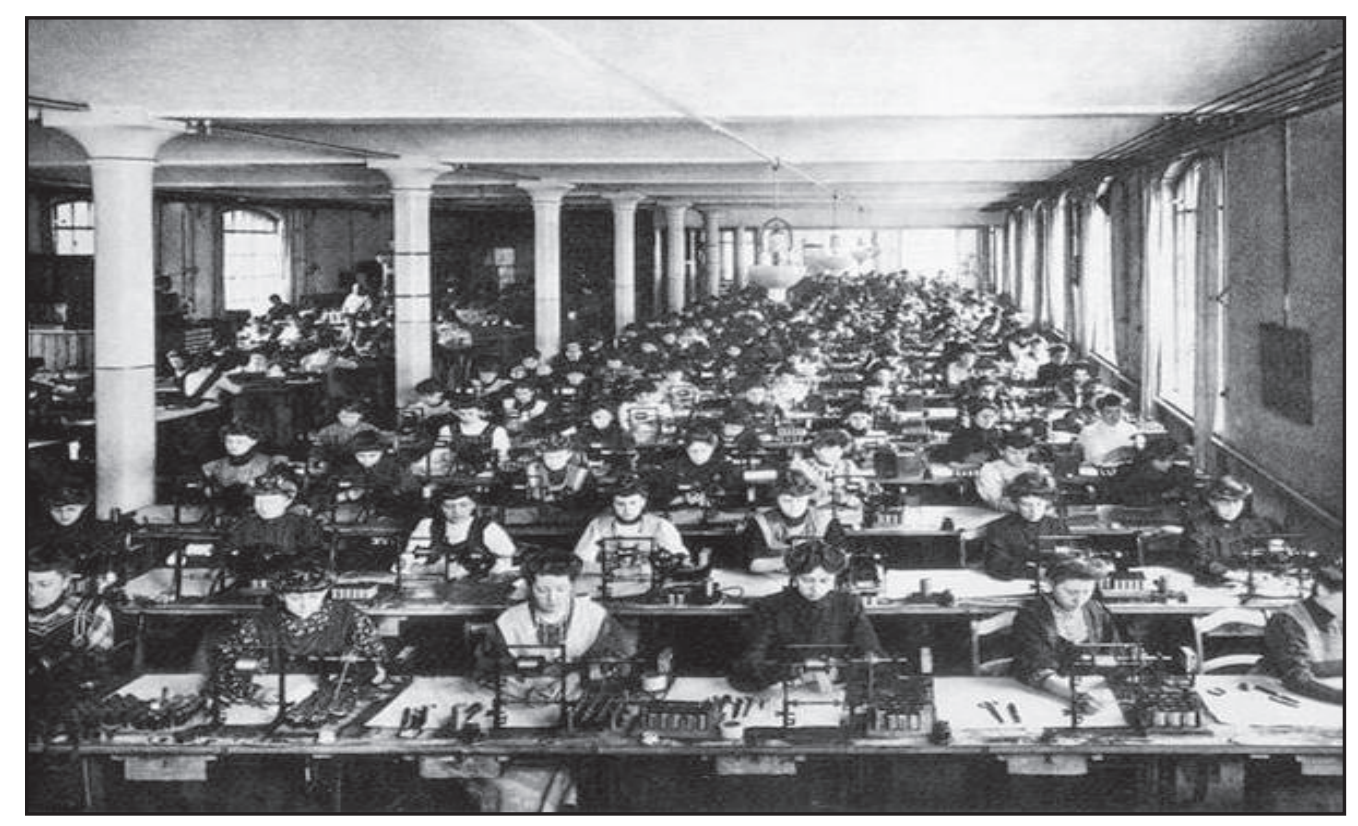

Fonte:<https://thesleepofreason.com/2015/09/24/death-to-the-pursuit-of-happiness/>. Acesso em: out. 2019

Inicialmente, entre os países que lideraram essa transformação social e organizacional, a universalização do acesso à educação formal ganhou urgência e se tornou um direito. Afinal, o trabalho sofreu expressivas modificações e isso exigia o desenvolvimento de habilidades até então desconhecidas, mas com chance de influir sobre a racionalização do trabalho orientada pela redução do tempo empregado e do custo de produção envolvido. Frente ao desafio de atingir um número crescente de estudantes, com investimentos relativamente modestos, a educação foi fortemente padronizada, reproduzindo a cultura do trabalho fabril, a linha de produção. Cabia ao professor controlar a presença em sala de aula, ensinar e avaliar fazendo uso dos mesmos recursos pedagógicos (exposições, exames orais e escritos) e supervisionar o trabalho escolar de dezenas de alunos. Separados por faixa etária, uniformizados, confinados em ambientes fechados e enfileirados em salas de aulas, os estudantes se submetiam à mesma grade curricular e a rígida disciplina, memorizavam os conteúdos e os devolviam em forma de exames. Individualmente, todos realizavam as mesmas atividades, usando as mesmas ferramentas (papel e lápis), regidos pelo mesmo relógio e avaliados pela mesma régua (HARARI, 2018). Lengel (2013) nomeia essa experiência de educação 2.0. 


\section{ANO 17 • NÚMERO 32 • JANEIRO/ABRIL 2020 • ORGANICOM \\ A TRANSFORMAÇÃO DO PROCESSO DE ENSINO \\ E APRENDIZAGEM NÃOÉ UM VOO DE GALINHA}

Foto 2 - Educação no contexto da Primeira Revolução Industrial.

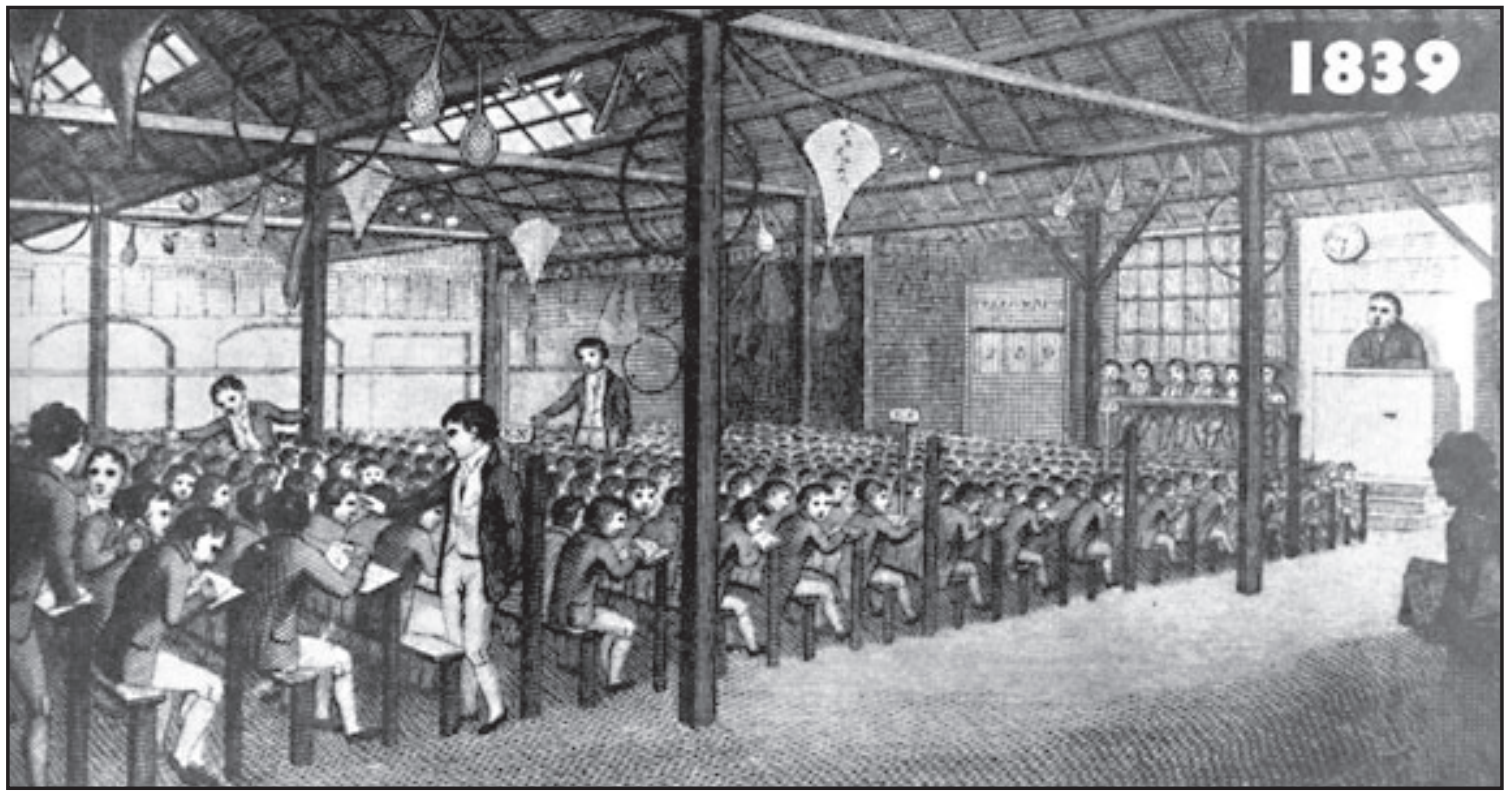

Fonte: < https://commons.wikimedia.org/wiki/File:Monitorial1839.jpg>. Acesso em: out. 2019.

Compreensivelmente, o acesso à educação formal cresceu na mesma velocidade com que cresceram as epidemias decorrentes da padronização, apesar da heterogeneidade de professores e estudantes. Isso potencializou o desinteresse pelos estudos, as dificuldades de aprendizagem e a evasão escolar (SOARES, 2018). Afinal, essa concepção de educação desconsidera as particularidades dos estudantes, seus interesses e respectivos propósitos, o desejo de ser desafiado, a possibilidade de se transformar (autoformação) e de transformar o meio (ecoformação). Apesar das rápidas transformações em curso, não faltam autores que assegurem a preservação das características típicas da era industrial, a exemplo de Manuel Castells ${ }^{3}$. Não seria essa uma das fontes que explicam a crise em que a educação está mergulhada? Referindo-se ao ambiente universitário, Alfredo Pena-Veiga (2012, p. 156) afirma que "há vários anos a universidade se encontra mergulhada em uma crise na medida em que insiste em se orientar pela concepção de produção típica da sociedade industrial”.

\section{GÊNESE E CARATERÍSTICAS DA CONCEPÇÃO DE EDUCAÇÃO NA ERA PÓS-INDUSTRIAL}

Contemporaneamente a realização do trabalho requer que as atividades sejam realizadas em times, cujos integrantes se mobilizam pelo desafio de formular problemas inéditos e elaborar soluções criativas, de forma colaborativa. Para tanto, trabalham orientados pelo conceito de design de projeto, em times flutuantes porque se configuram e reconfiguram em redes, de acordo com as competências requeridas pelos desafios presentes em cada novo projeto (MOTA; SCOTT, 2014). Para tanto, os trabalhadores dependem da capacidade de explorar múltiplas linguagens (poliglotismo cultural) (RIBEIRO, 2001), dispor de recursos técnicos, teóricos e metodológicos transversais (multi-inter-transdisciplinar) (MORIN, 2004) ${ }^{4}$, além de disposição para trabalhar com ferramentas digitais que colaborem para a coleta e tratamento dos dados que fundamentarão as alternativas de solução para problemas inéditos e relevantes (DEMO, 2012).

Isso requer estágios cada vez mais elevados de letramento digital (digital literacy) ou fluência digital (digital fluency), inclusive letramento informacional. Fernanda Rosa e Maria Carolina Dias (2012, p. 51) definem letramento digital como "a condição que permite ao sujeito usufruir das tecnologias de informação e comunicação para atender às necessidades do seu meio social e se desenvolver autonomamente na sociedade da informação". Para as autoras, a sua operacionalização se dá por meio da conjunção de duas dimensões de habilidades funcionais: a técnico-operacional e a

3 Em vídeo publicado em 2014, Manuel Castells reflete sobre a obsolescência da educação enfatizando como as práticas de educação 2.0 prevalecem na sociedade intensiva de conhecimento Cf. <https://www.youtube.com/watch?v=eb0cNrE3I5g>.

40 pensamento complexo vê o mundo como um todo indissociável. Propõe uma abordagem multidisciplinar e multirreferenciada para a construção do conhecimento. Entende que não há realidade sem a consciência do sujeito (MORIN, 2005). 
informacional. Enquanto a primeira envolve os conhecimentos necessários para manuseio das tecnologias de informação e comunicação e de suas ferramentas; a segunda implica a capacidade de manusear e integrar informações de diferentes níveis e formatos em ambiente digital, para que estas se transformem em conteúdos úteis, que respondam a finalidades intencionais do indivíduo. Elas envolvem a capacidade de avaliar informações e situações a que se está submetido no uso das tecnologias de informação e comunicação (TICs), em termos de validade e segurança, e de compreender padrões de funcionamento que permitam ao indivíduo desenvolver-se autonomamente neste ambiente (ROSA; DIAS, 2012).

Na contemporaneidade, as tecnologias de informação e comunicação interferem enormemente na forma como se vive, particularmente sobre como se aprende e se trabalha. Observa-se que indivíduos fluentes em tecnologia da informação estão mais instrumentalizados para aprender permanente e criativamente, com mais velocidade e autonomia (auto e heteroformação). Consequentemente, a fluência em tecnologia da informação favorece o processo de aprendizado vitalício, permitindo que os indivíduos utilizem o que sabem para promover e se adaptar às mudanças, serem mais efetivos no uso da tecnologia da informação não apenas nos ambientes acadêmico e profissional, mas também na vida cotidiana (ROSA; DIAS, 2012, p. 44).

Essa concepção de trabalho pressupõe aprendizagem contínua e a ausência de separação entre vida e trabalho. Isso equivale a afirmar que individual e/ou coletivamente, cada pessoa é responsabilizada pelo próprio processo formativo, e nesse contexto o trabalho ocupa todas as esferas da vida. Assim sendo, a adoção de supervisão próxima não faz qualquer sentido ${ }^{5}$. Estas são características típicas do ambiente de trabalho 3.0. No momento em que a crescente substituição do trabalho humano pelas máquinas tem colaborado para imprimir um caráter cada vez mais imaterial ao trabalho, elevando a natureza cognitiva das atividades profissionais, questiona-se em que medida as instituições educacionais estão colaborando para formar pessoas em geral e profissionais, em particular, capazes de atuar nesse ambiente? Até que ponto os órgãos reguladores da educação (nacional e internacional) têm compreendido a extensão e profundidade das mudanças requeridas pela sociedade intensiva de conhecimento e exigente em aprendizagem? ${ }^{6}$ Até que ponto as instituições educacionais, lideranças acadêmicas, professores e estudantes estão sensíveis à necessidade de imprimir transformações substantivas à educação do século XXI, assumindo o desafio intrínseco ao processo de mudança e às novas responsabilidades requeridas de cada sujeito implicado no processo que envolve ensino e aprendizagem?

Ao estabelecer algum nível de comparação entre a educação 2.0 e a educação 3.0,é possível afirmar que enquanto a primeira está orientada por uma ideia simples, singular, linear, unitária, fragmentada, delimitada e analítica do conhecimento, a segunda reconhece o conhecimento como algo complexo, heterogêneo, não linear, integrativo, conectado, irrestrito, dialogado e colaborativo. Assim sendo, a concepção de educação 3.0 se orienta pelo desafio de mobilizar um conjunto de recursos que contribua para a promoção da aprendizagem significativa entre os estudantes. ${ }^{7}$ Nessa direção, cabe às instituições educacionais liderarem um movimento de transformação em seis direções:

- Gestores acadêmicos: entender o contexto do processo de transformação que tem requerido um novo paradigma pedagógico, orientado pela e para a aprendizagem dos estudantes;

- Formação pedagógica dos professores: contribuir para a ampliação das competências docentes à medida que, além de domínio técnico, teórico e metodológico em determinado campo de conhecimento, se faz mister que os professores tenham familiaridade com as teorias da aprendizagem que imprimirão sentido à escolha dos recursos didáticopedagógicos, e atinjam elevado nível de letramento digital ${ }^{8}$ para que possam explorar o potencial aberto pelas redes sociais à medida que as plataformas, a produção e a comunicação colaborativas ganham especial destaque no processo de ensino e aprendizagem;

\footnotetext{
5 Nas organizações industriais, supervisor "é aquele que dirige, controla, vigia, cuida de tudo e se responsabiliza para que tudo se faça corretamente e de maneira segura" (BOTTI; REGO, 2008, p. 366).

6 Observa-se que as mudanças implicadas assumem um caráter sistêmico e estrutural, por isso mesmo mais próximo do conceito de revolução e mais distante da ideia de reforma.

7 Sobre o conceito de aprendizagem significativa, recomenda-se a leitura do texto de Moreira e Masini (2010).

8 Letramento digital corresponde ao conjunto de competências necessárias para que determinado indivíduo localize, selecione, interprete e aplique dados e informações originários de distintas fontes de consulta, disponibilizados em mídia digital, em múltiplos formatos, de maneira crítica e estratégica quando se leva em conta os objetivos justificadores, não raro, compartilhados social e culturalmente (FREITAS, 2010, p .339-340; MOTA e SCOTT, 2014, p.45-46).
} 
- Estudantes: cultivar uma cultura acadêmica e pedagógica que colabore para um processo capaz de promover o autoconhecimento, a autonomia, a autoformação e a autorregulação;

- Currículo: adotar arquiteturas curriculares flexíveis, modulares, afeitas a abordagens transversais e à construção de itinerários capazes de respeitar os propósitos (projetos) que mobilizam não apenas a atenção, mas o interesse dos estudantes;

- Espaços de aprendizagem: ampliar e diversificar os espaços de aprendizagem, sejam eles físicos, virtuais ou híbridos.

\section{CURIOSO PARADOXO: EMERGÊNCIA DA SOCIEDADE INTENSIVA DE CONHECIMENTO E CRISE NO SISTEMA EDUCACIONAL}

Nos últimos vinte anos, os sinais que apontam para a instalação de uma multicrise na educação não são modestos. No Brasil, um indício disso é a pouca qualidade dos cursos de graduação: 1/4 dos cursos de nível superior avaliados pelo Ministério da Educação com a aplicação do Exame Nacional de Desempenho de Estudantes (ENADE) em 2016 foi reprovado. De 4,3 mil graduações avaliadas, enquanto $27 \%$ obtiveram notas 1 e 2 (consideradas insatisfatórias), $40 \%$ obtiveram conceito $3 ; 25 \%$ atingiram conceito 4 ; e apenas $6 \%$ atingiram conceito 5 . Outro indício é a diminuição do número de ingressantes na educação superior associada ao crescente índice de evasão ${ }^{9}$. Se considerarmos cinco anos consecutivos (2012-2016), é possível constatar a redução do número de ingressantes entre as instituições particulares, sobretudo o abismo existente entre o número de ingressantes e concluintes dos cursos superiores no formato presencial (quadro 1).

Quadro 1 - Ingressantes e concluintes de IES públicas e particulares (2012-2016).

\begin{tabular}{|c|c|c|c|c|}
\hline Ano-base & $\begin{array}{c}\text { Ingressantes em } \\
\text { IES públicas }\end{array}$ & $\begin{array}{c}\text { Concluintes em } \\
\text { IES públicas }\end{array}$ & $\begin{array}{c}\text { Ingressantes em } \\
\text { IES privadas }\end{array}$ & $\begin{array}{c}\text { Concluintes em } \\
\text { IES privadas }\end{array}$ \\
\hline $\mathbf{2 0 1 2}$ & 499.570 & 202.464 & 1.714 .507 & 679.271 \\
\hline $\mathbf{2 0 1 3}$ & 495.159 & 206.353 & 1.739 .234 & 627.361 \\
\hline $\mathbf{2 0 1 4}$ & 504.835 & 225.897 & 1.881 .923 & 614.831 \\
\hline $\mathbf{2 0 1 5}$ & 504.237 & 224.351 & 1.723 .604 & 694.384 \\
\hline $\mathbf{2 0 1 6}$ & 505.162 & 231.666 & 1.638 .293 & 708.576 \\
\hline
\end{tabular}

Fonte: Censo Inep, 2017

Isso equivale a afirmar que o índice de evasão observado nas IES brasileiras evolui a cada ano, e o percentual tem sido mais pronunciado entre as instituições particulares (quadro 2). Isso requer atenção para se diagnosticar as motivações uma vez que se trata de um fenômeno multicausal (SILVA, 2017).

Quadro 2 - Evasão em IES públicas e particulares (\%).

\begin{tabular}{|c|c|c|}
\hline Ano-base & $\begin{array}{c}\text { Evasão em IES } \\
\text { públicas (\%) }\end{array}$ & $\begin{array}{c}\text { Evasão em IES } \\
\text { particulares (\%) }\end{array}$ \\
\hline $\mathbf{2 0 1 2}$ & 17,2 & 27,7 \\
\hline $\mathbf{2 0 1 3}$ & 17,8 & 27,4 \\
\hline $\mathbf{2 0 1 4}$ & 18,3 & 27,9 \\
\hline $\mathbf{2 0 1 5}$ & 18,4 & 28,6 \\
\hline $\mathbf{2 0 1 6}$ & 18,5 & 30,1 \\
\hline
\end{tabular}

Fonte: Censo Inep, 2017.

De acordo com o Mapa do Ensino Superior no Brasil (SEMESP, 2018, p.21), levando-se em conta os dados referentes à evasão no primeiro ano do curso escolhido ${ }^{10}$, observa-se que eles apresentam discreta variação entre as instituições públicas, mas expressiva variação entre estudantes com ou sem financiamento (quadro 3), sinalizando que em um

9 Evasão equivale ao total de estudantes com matrículas trancadas, desvinculação do curso e falecidos.

10 A taxa de evasão no primeiro ano corresponde ao número de estudantes que ingressaram em determinado curso menos o número de estudantes que trancaram a matrícula, se desvincularam ou se transferiram do curso (SEMESP, 2018, p.21). 


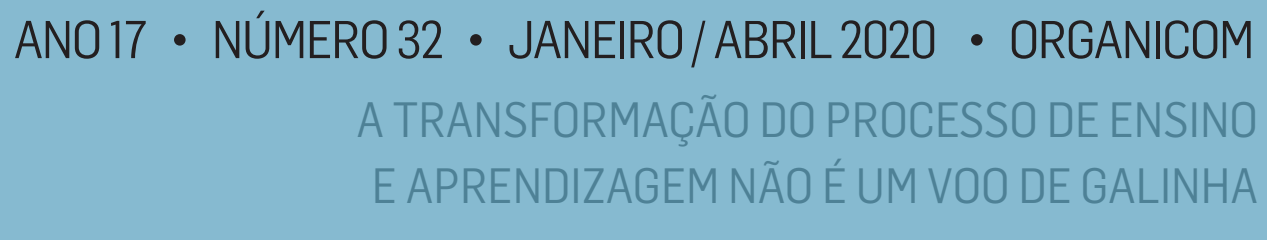

país que preserva acentuada desigualdade social, as instituições públicas são importantes e o financimento da educação superior é imprescindível, preocupações que estão na contramão do que se tem assistido nos últimos anos, particularmente no atual governo.

\section{Quadro 3 - Evasão - IES públicas e particulares (com e sem financimento).}

\begin{tabular}{|c|c|c|c|c|}
\hline Ano-base & $\begin{array}{c}\text { Evasão: } \\
\text { IES públicas }\end{array}$ & $\begin{array}{c}\text { Evasão: } \\
\text { IES privadas sem } \\
\text { financiamento }\end{array}$ & $\begin{array}{c}\text { Evasão: } \\
\text { IES privadas } \\
\text { com Fies }\end{array}$ & $\begin{array}{c}\text { Evasão: } \\
\text { IES privadas } \\
\text { com Prouni } \\
\text { (parcial/ integral) }\end{array}$ \\
\hline $\mathbf{2 0 1 2}$ & & $24,9 \%$ & $6,4 \%$ & $10,6 \%$ \\
\hline $\mathbf{2 0 1 3}$ & & $24,0 \%$ & $6,7 \%$ & $11,3 \%$ \\
\hline $\mathbf{2 0 1 4}$ & $14,4 \%$ & $27,4 \%$ & $7,4 \%$ & $11,8 \%$ \\
\hline $\mathbf{2 0 1 5}$ & $14,2 \%$ & $26,5 \%$ & $7,4 \%$ & $11,8 \%$ \\
\hline $\mathbf{2 0 1 6}$ & $14,1 \%$ & $26,0 \%$ & $9,7 \%$ & $9,8 \%$ \\
\hline
\end{tabular}

Fonte: Semesp (2018, p.21).

Outro indício é o desinvestmento em educação. A mídia tem noticiado que entre 2014 e 2018 o investimento em educação no País encolheu de $\mathrm{R} \$ 11,3$ bilhões para $\mathrm{R} \$ 4,9$ bilhões. Mas esse valor é ainda mais modesto uma vez que a projeção da Lei Orçamentária de 2019 prevê $\mathrm{R} \$ 4,2$ bilhões. Trata-se de um movimento suicida, uma vez que pode inviabilizar o funcionamento das universidades públicas ainda em 2019. Títulos publicados por editoras nacionais e internacionais sinalizam que a crise se estende por todos os níveis de formação, atingindo países centrais e periféricos com distintas intensidades. Seguem alguns exemplos meramente ilustrativos.

Figura 1 - Exemplos de títulos publicados por editoras nacionais e internacionais.

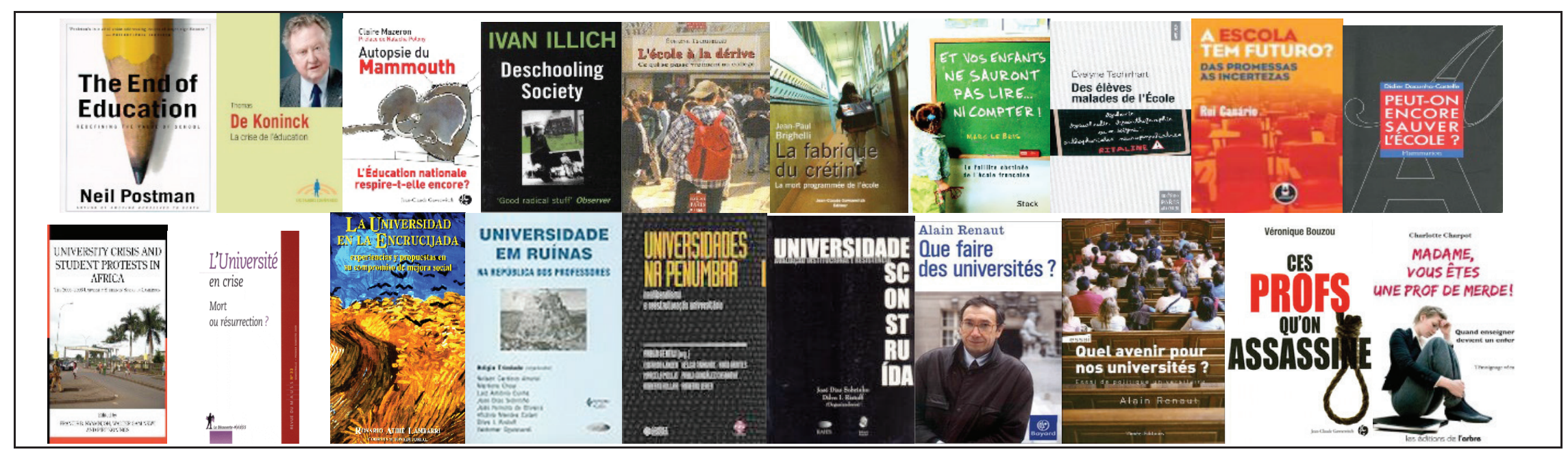

Fonte: Seleção feita pelo autor.

As distintas dimensões da referida crise levam Pena-Veiga (2012) a afirmar a existência de uma multicrise, um verdadeiro paradoxo quando se leva em conta a centralidade do conhecimento na contemporaneidade. As reflexões aqui propostas irão se concentrar em aspectos relativos ao processo que envolve o ensino e a aprendizagem. Compreensivelmente, quando se altera a chave do ensino orientado para a aprendizagem, as mudanças ocorrem em todos os níveis e, simultaneamente, perde-se a referência dos bons professores com quem se teve a oportunidade de trabalhar como o elemento orientador da prática docente!

Possivelmente, a crise reflita um processo de transição exigente, particularmente complexo, uma vez que implica uma mudança de paradigma pedagógico. Sobretudo quando os espaços de resistências não são modestos. Em 1999, referindo-se à educação brasileira, Pedro Demo afirmava que tanto as escolas quanto as universidades preservam o instrucionismo ao reproduzirem o conhecimento estocado. Em 2014, referindo-se à educação brasileira e inglesa, 
Ronaldo Mota e David Scott (2014, p. 17-18) asseguravam que "enquanto o reconhecimento social dos professores tem continuamente decrescido, contraditoriamente, há crescente percepção geral na sociedade sobre a importância da educação e do papel dos professores como elementos essenciais para melhorar o sistema educacional". 0 que poderia explicar essa contradição? Mesmo levando em conta as condições adversas, o texto em tela buscará situar alguns elementos reunidos na figura 2 .

Figura 2 - Desafios da aprendizagem.

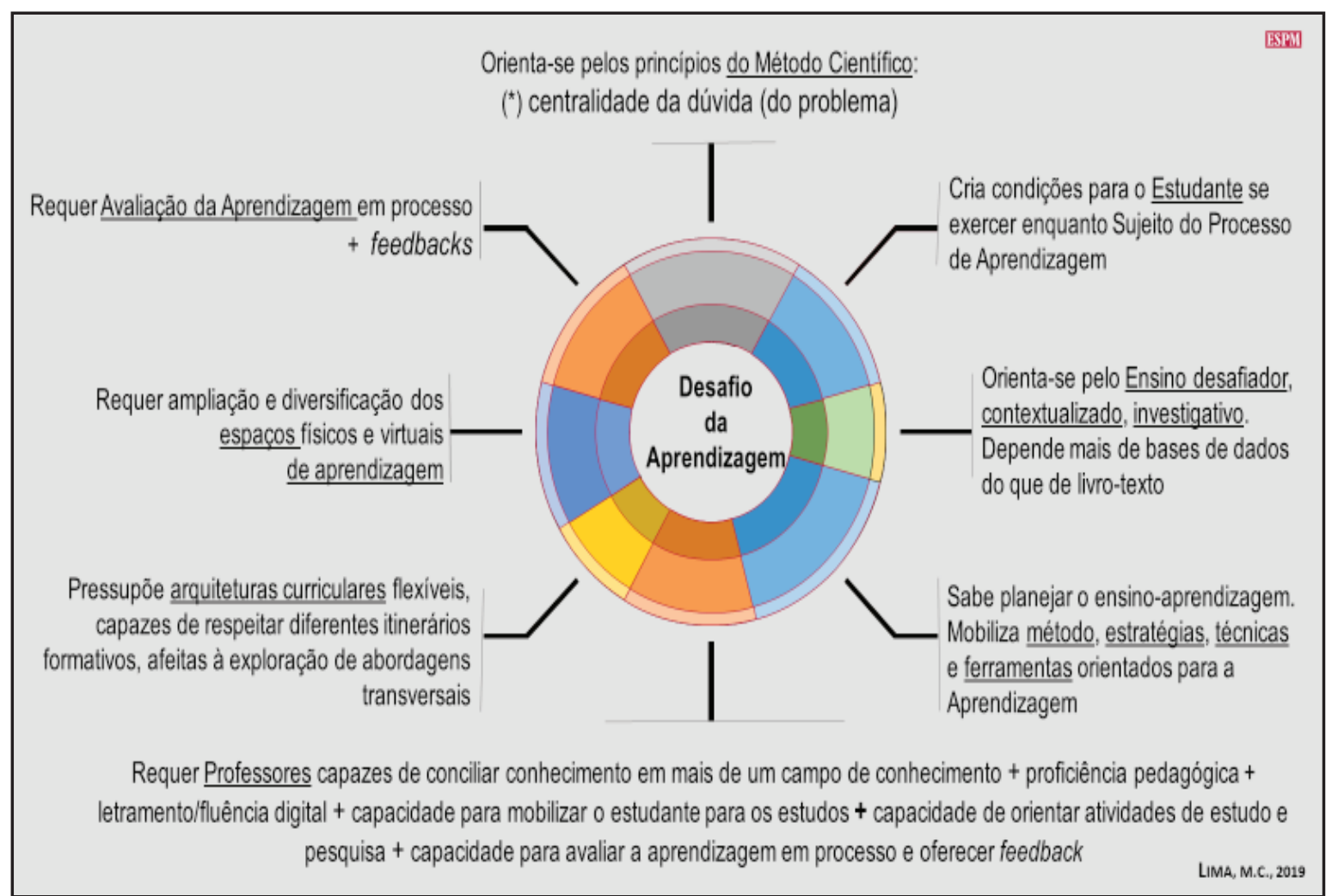

Fonte: Manolita Correia Lima, 2019.

No conjunto, a articulação dos oitos itens reunidos na figura 1 requer dedicação em tempo e esforço porque pressupõe um processo de mudança de cultura: os alunos ganham o status de estudantes; os professores assumem múltiplas responsabilidades (educador, orientador, tutor, mediador, mentor, facilitador, instrutor, curador, designer educacional etc.), os gestores acadêmicos ganham as feições de um líder visionário e os técnicos-educacionais auxiliam de diferentes maneiras o processo de transformação requerido. As alterações observadas nos termos recorrentemente utilizados no ambiente educacional são muito reveladoras do processo de transformação em curso (quadro 4), como será possível perceber na continuidade do texto.

\section{Quadro 4 - A aprendizagem inspira alterações nos termos.}

\begin{tabular}{|l|l|}
\hline \multicolumn{1}{|c|}{ Ensino } & \multicolumn{1}{c|}{ Aprendizagem } \\
\hline Aluno & Estudante, aprendiz \\
\hline Instrutor, mestre, professor & $\begin{array}{l}\text { Educador, tutor, curador de conteúdos, mentor, mediador, orientador, facilitador, } \\
\text { designer educacional, influenciador digital }\end{array}$ \\
\hline Grade curricular & Desenho, arquitetura, matriz curricular \\
\hline Turma & Comunidade de aprendizes \\
\hline Sala de aula & Espaços de aprendizagem (presencial, vitual, híbrido) \\
\hline Programa & Plano de ensino e aprendizagem \\
\hline Aula & Atividades de ensino-aprendizagem \\
\hline
\end{tabular}

Fonte: Manolita Correia Lima, 2019 


\section{ANO 17 • NÚMERO 32 • JANEIRO/ABRIL 2020 • ORGANICOM \\ A TRANSFORMAÇÃO DO PROCESSO DE ENSINO \\ E APRENDIZAGEM NÃO É UM VOO DE GALINHA}

\section{CENTRALIDADE DO CONHECIMENTO E SUA INFLUÊNCIA SOBRE O CURRÍCULO}

Dos anos 1990 em diante a universidade sofre uma erosão sem precedentes em suahegemonia, decorrente principalmente das transformações na produção do conhecimento, com a intensificação do processo de transição do conhecimento universitário convencional para o conhecimento pluriversitário, transdisciplinar, contextualizado, interativo, produzido, distribuído e consumido com base nas tecnologias de comunicação e de informação capazes de alterar as relações entre conhecimento e informação, formação e cidadania (SANTOS, 2010). Soma-se a isso o fato de, no ingresso no século XXI, o conhecimento conquistar centralidade em todas as esferas da existência, particularmente na econômica. Isso explica o fato de expressões como indústria do conhecimento (utilizada por Tony Blair), sociedade da informação (utilizada pela Comissão Europeia), sociedade de conhecimento (expressão que deu título a um relatório da Unesco publicado em 2005), sociedade intensiva de conhecimento (DEMO, 2011), economia intensiva de conhecimento, sociedade baseada na economia do conhecimento, capitalismo cognitivo (CORRÊA, CHAVES e SOUSA, 2018; Pena-Veiga, 2012) e civilização cognitiva ganharem espaço no ambiente acadêmico - capaz de problematizar o debate - e na mídia - sempre mais afeita a um discurso apologético dessas expressões.

A tecnologia digital subverte a ideia de tempo e espaço - aprendemos cada vez mais cedo, o tempo todo, em qualquer lugar -, contribuindo sobremaneira para o crescimento exponencial da velocidade e da quantidade de dados e informações em circulação. Apesar de o Brasil ser uma nação semiperiférica, a proporção de pessoas com acesso às tecnologias digitais impressiona. Mas quem é capaz de selecionar dados e informação confiáveis e transformá-los em conhecimento? Esse processo depende de competências desenvolvidas no âmbito da educação formal! Nesse contexto, as responsabilidades docentes e discentes ganham novos contornos, dar aula e assistir a aulas perdem sentido e razão de ser.

Figura 3 - Dados sobre o acesso às tecnologias digitais.

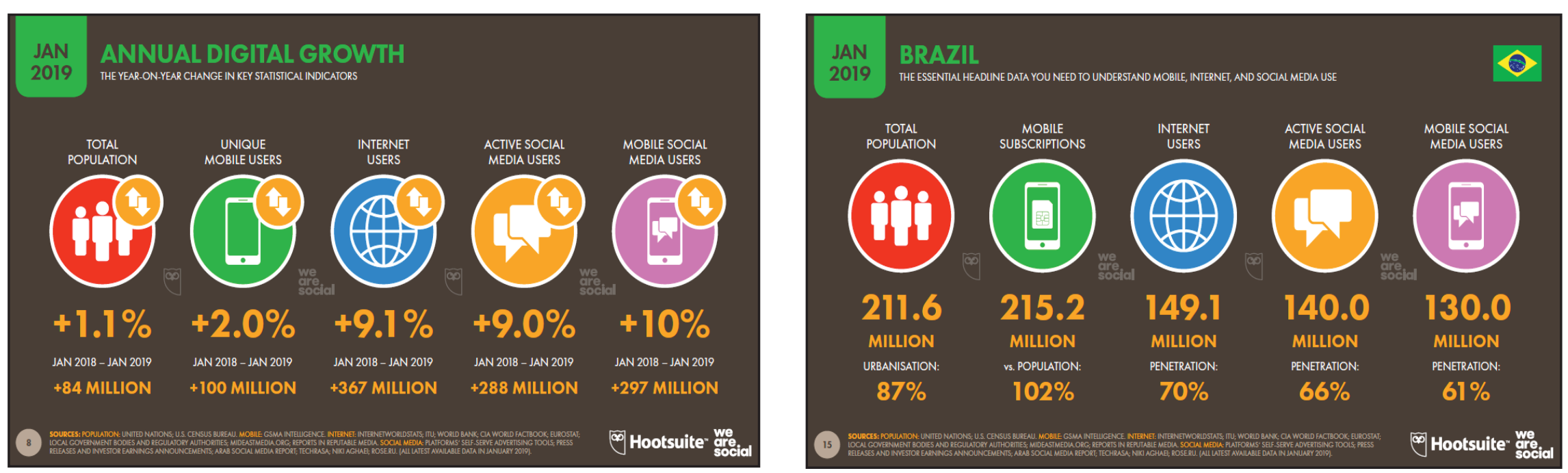

Fonte: < https://pt.slideshare.net/DataReportal/digital-2019-brazil-january-2019-v01>..Acesso em out.2019.

Em tempo algum houve tanta produção, difusão e acesso a dados e informações, reforçando a pertinência do conceito de ciberdemocracia (LÉVY, 2002). Frente ao exposto, faz pouco sentido reduzir o conhecimento a produto; o professor, a mero repassador de estoques de conteúdos ordeiramente empacotados em disciplinas, livros texto ou apostilas; o estudante, a um receptor passivo de dados e informações; a relação entre professores e estudantes, a ensino; e as atividades educacionais, à sala de aula! Na contemporaneidade, o desafio da educação consiste em trabalhar o conhecimento como produto, sobretudo como processo, contando com as múltiplas responsabilidades do professor - educador, tutor, curador de conteúdos, mentor, mediador, orientador, facilitador, designer educacional etc. - e do estudante - aprendente, pesquisador, autor etc. -, ampliando as comunidades de aprendizes, diversificando e qualificando os espaços de aprendizagem, uma vez que a relação entre professores e estudantes é cada vez mais definida por atividades de ensino orientadas pela e para a aprendizagem. 
Esse ambiente de visível efervescência tem favorecido a obsolescência de grande parte dos conteúdos e a constatação de que "a inteligência inventiva" se manifesta quando nos afastamos do saber acumulado (SERRES, 2013). Assim, reafirmase que trabalhar com estoques fixos de conhecimento (ensino escaneado) é menos importante do que mobilizar a capacidade de estudantes problematizarem, localizarem, selecionarem, organizarem, analisarem / interpretarem dados e informações, orientados pelo desafio de gerar conhecimento novo, de forma colaborativa, em uma dinâmica que transita entre construção, desconstrução e reconstrução do conhecimento. Consequentemente, mais do que aprender, os ambientes de estudo e trabalho requerem competências que favoreçam o aprender a aprender (DEMO, 2012) e a aprendizagem ao longo da vida (lifelong learning).

Aprender a aprender contribui para a formação de pessoas técnica, teórica e metodologicamente potentes, capazes de aprender permanentemente, de forma autônoma e aplicar o conhecimento gerado em distintos contextos, adubando o processo de transformação implicado na autoformação, heteroformação e ecoformação, na trilha da teoria tripolar da formação humana, proposta por Gaston Pineau (1988, apud BRAGANÇA, 2011). Assim, o espaço/tempo de estudo e o espaço/tempo de trabalho são cada vez mais inseparáveis (DEMO, 2009). Essa competência tem sido reconhecida como essencial até mesmo pelos autores pragmáticos à medida que influi sobre a formação de sujeitos, consequentemente sobre a produtividade e a inovação, aspectos determinantes da elevação da competitividade (MOTA; SCOTT, 2014).

Essa visão reforça a importância de o conhecimento ser permanentemente colocado em dúvida (problematizado) e poder refletir a melhor solução possível, considerando o tempo presente. Imprimir a visão que reconhece o conhecimento como algo inacabado, provisório e histórico, responsabiliza as novas gerações pela formulação de novos problemas e pela busca de soluções ajustadas aos desafios de seu tempo (DEMO, 2012). Assim sendo, os ambientes de ensino e aprendizagem, sejam eles físicos, virtuais ou híbridos, são construídos em torno de problemas preferencialmente inéditos, cuja relevância justifica a busca de alternativas de solução (BÉDARD; BÉRCHARD, 2009). As soluções requerem atitude investigativa: curiosidade, capacidade de problematizar (FREIRE, 1985) ${ }^{11}$, capacidade de leitura e interpretação (FREIRE, 1988), troca de experiências, acesso a múltiplas fontes de dados, organização e interpretação dos dados, formulação de alternativas de soluções criativas e inovadoras (DEMO, 2012). No âmbito de uma educação orientada para o trabalho, estar-se no universo do analista simbólico, descrito por Robert Reich (2005) e de uma educação sensível à inovação (MOTA; SCOTT, 2014).

O período que marcou o final do século XX coincide com admirável incremento das tecnologias de informação, particularmente com a emergência da internet e das possibilidades abertas por ela. Com isso, houve enorme avanço nas tecnologias que viabilizam a troca de dados por meio de sistemas ciber-físicos capazes de monitorar os processos físicos, criar cópia virtual do mundo físico e propiciar a tomada de decisões descentralizadas. A internet das coisas permite que os sistemas ciber-físicos comuniquem e cooperem entre si e com os humanos, em tempo real. A computação em nuvem, por sua vez, permite a oferta de serviços internos e intraorganizacionais utilizados pelos participantes da cadeia de valor (CAMANHO, 2018). Observa-se que a revolução promovida pelas tecnologias de informação tem exercido importantes transformações em todas as dimensões da vida humana, da arte à ciência, a exemplo da arte interativa e imersiva, machinimas, videoarte, animações de arte, games, gifs, robótica, animatrônica, inteligência artificial, LED show, além das performances reunidas nos vinte anos de existência do Festival Internacional de Linguagem Eletrônica (File) ${ }^{12}$.

Nesse contexto, os valores, o estilo de vida e o comportamento dos jovens (particularmente os nativos digitais) ${ }^{13}$ mudam substancialmente; a produção e difusão de dados, informações e conhecimento ganham novos formatos e distintas dinâmicas; os ambientes de trabalho sofrem importantes alterações e tudo isso repercute sobre as competências que merecem ser desenvolvidas pelos habitantes deste planeta, em acelerado processo de transformação, que tanto podem ser associadas a uma visão otimista do futuro (Peter Schwartz; Michel Serres), quanto a instalação de um processo de decadência (Michel Onfray; Yuval Noah Harari).

11 Problematizar enfatiza a práxis na qual o sujeito busca soluções para a realidade em que vive e se torna capaz de transformá-la pela própria ação, ao mesmo tempo em que se transforma.

12 Para mais informação sobre o File, cf. <http://centroculturalfiesp.com.br/evento/file-sao-paulo-2019>.

13 Os termos imigrante digital e nativo digital foram cunhados por Marc Prensky. Enquanto imigrante define pessoas que nasceram em data anterior a 1980, valorizam a tecnologia analógica, desconhecem ou conhecem muito pouco o funcionamento das tecnologias digitais; o nativo digital é aquele que tem familiaridade com as tecnologias digital de informação e comunicação porque desde a primeira infância têm contato frequente com videogames,ilnternet, telefone celular, MP3, MP4, MP5 Players, iPod, iPed etc. 
Os jovens que crescem em um ambiente marcado pela cultura digital estão mais familiarizados com sistemas artificiais inteligentes e informação digitalizada. Mas, não raro, atravessam os muros das instituições educacionais e encontram verdadeiras "grades" curriculares, recheadas de disciplinas obrigatórias, pré-requisitos, surpreendente valorização de extenso conteúdo, cuja "entrega" requer elevada carga horária e a adoção de métodos reprodutivos, aplicação de exames em que os resultados legitimam decisões de aprovação ou reprovação - estamos no universo do ensino dissociado da aprendizagem! Do ensino escaneado, pouco contributivo para a formação de sujeitos reflexivos e para o desenvolvimento de competências que trasitam entre a inteligência social, competência transcultural, mentalidade de design, pensamento computacional, formação de redes e colaboração virtual, capacidade de gerar significado, capacidade de gerenciar elevada carga cognitiva, capacidade de pensar de forma indepente (MOTA; SCOTT, 2014), e o que Yuval Harari (2018) nomeia de os 4 Cs: pensamento crítico, comunicação, colaboração e criatividade.

No contexto em questão, os estudantes tendem a estabelecer outra relação com o saber ${ }^{14}$, imprimirão sentido a projetos educacionais distintos, aprenderão de maneiras diferentes, estabelecerão outra relação com os professores e as instituições educacionais. Aqui emerge um hiato que ajuda a explicar o desinteresse crescente dos jovens pela escola e pelos estudos, a desmobilização decorrente e a evasão crescente. Se as instituições educacionias insistirem em preservar a aula instrucional, essa nova geração digital tomará a dianteira e decretará o sepultamento desse tipo de escola (DEMO, 2001) e de um professor reduzido a instrutor. Cabe lembrar que isso já foi reivindicado pelos estudantes que promoveram o movimento de Córdoba, em 1918, nos termos de Carlos Tünnermann Bernheim (2008, p. 93): "la Reforma también abogó por la introducción de nuevas metodologías de docencia. La metodología activa fue su principal postulado en este aspecto, coincidiendo con las corrientes educativas de la época, que veían en la classe magistral un anacronismo pedagógico". Contudo, essa discussão remonta a Immanuel Kant (1724-1804), para quem a nova pedagogia trata de aproximar a educação da vida, de modo que os alunos possam compreendê-la para transformá-la; e a Johann Gottlieb Fichte (1762-1814), que em oposição a aprendizagem mecânica, de utilidade incerta, afirmava ser necessário que tudo que se aprende seja entendido como a consciência clara do fato de que se adquire o conhecimento de forma ativa, e com a consciência das regras dessa atividade de aquisição.

Ciente de que o ensino orientado pela aprendizagem requer respeito às necessidades educacionais dos estudantes, como criar condições que favoreçam a aprendizagem? Como os professores podem promover a aproximação intrínseca entre ensino e aprendizagem significativa ou experiencial (ROGERS, 1971), expansiva (ENGESTRÖM, 1987), transicional (ALHEIT, 2013), transformadora (MEZIROW, 2013)? Esse é o desafio da inovação pedagógica enfrentado pelos autores que assinam a obra colegiada organizada por Denis Bédard e Jean-Pierre Béchard, intitulada Inover dans l'enseignemet supérieur.

\section{O CURRÍCULO NO CONTEXTO DA EDUCAÇ̃̃O PÓS-INDUSTRIAL}

Até recentemente, o currículo prolongava um ideal iluminista das ciências (século XIX), com resquícios do enciclopedismo (século XVIII). Os cursos de graduação preservam uma espécie de introdução a determinada área, em uma tentativa de familiarizar o estudante com os fundamentos do campo de conhecimento escolhido. Nesse contexto, um bom curso e uma disciplina exemplar são aqueles que se prestam a "entregar muito conteúdo" e por isso mesmo requerem elevada carga horária. Não raro, tenta-se estabelecer algum equilíbrio entre conteúdos teóricos e saberes práticos, trabalhados nessa sequência, de forma dissociada. Dessa feita, os dois, três, quatro, cinco ou seis anos do curso de graduação se tornam cada vez mais insuficientes quando se objetiva explorar o conhecimento incessantemente produzido. Invariavelmente, a solução encontrada reside em o professor resumir o estado da arte e transmitir o conteúdo em forma de aulas expositivas, por vezes interessantes, mas pouco contributivas quando a preocupação reside em criar ambientes favoráveis à aprendizagem. Resgatando Bauman, o mundo líquido envolve projetos cuja realização requer competências que ultrapassam a memorização.

14 Sobre a relação com o saber, recomenda-se a leitura de Os jovens e o saber: perspectivas mundiais (CHARLOT, 2001). 


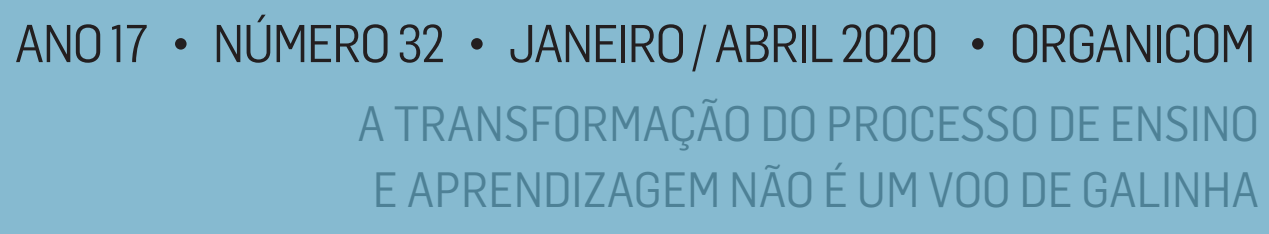

No passado, afirma Harari (2018), isso faria sentido, porque a informação era escassa e mesmo o lento cotejar da informação disponível era repetidamente bloqueado pela censura. No século XXI, completa o autor, tem-se acesso a enormes quantidades de informação, nem mesmo os censores tentam bloqueá-las. Em vez disso, disseminam informações falsas e distraem os indivíduos com irrelevâncias. Em um mundo assim, a última coisa que um professor precisa é munir os estudantes com informação, porque eles já têm informação em abundância. Em vez disso, os estudantes precisam desenvolver capacidade para extrair sentido da informação, reconhecer o que é relevante e irrelevante, acima de tudo combinar os muitos fragmentos de informações num amplo quadro de referência do mundo (HARARI, 2018).

$\mathrm{O}$ autor argumenta que a habilidade para lidar com mudanças, a capacidade de aprender coisas novas e de preservar $\mathrm{o}$ equilíbrio mental em situações pouco familiares correspondem às competências essenciais para se viver no século XXI, os desafios trazidos pela pademia são ilustrativos do que o autor deseja expressar. Em um mundo regido por rápidas transformações, faz-se mister desenvolver uma mente inquieta, investigativa, criativa, mas, acima de tudo, capaz de se reinventar diversas vezes. Pois à medida que o ritmo das mudanças aumenta, esclarece Harari (2018), é provável que não apenas a economia, mas o próprio sentido de "ser humano" mude. A lógica que embalou as gerações até o século XX - a primeira etapa da vida é dedicada aos estudos; a segunda (nomeada de 'vida útil'), ao trabalho; e finalmente a terceira e última, ao ócio permitido pela aposentadoria. Contudo, as mudanças aceleradas e a vida mais longa desconstroem essa linha do tempo e o modo de pensar a existência humana. Espera-se cada vez mais descontinuidades entre os diversos períodos da vida. A velocidade das mudanças associadas ao ambiente marcado por incertezas e descontinuidades favorece a elevação do nível de estresse, ansiedade, depressão, desencadeando, distúbios emocionais importantes (HARARI, 2018). Para o indivíduo sobreviver nesse ambiente precisará aprender sempre e se reinventar, independentemente da idade, o que requer múltiplas inteligências e flexibilidade mental. Quando a ênfase do processo educacional recai em conteúdo, desconsidera-se que grande parte do que se aprende hoje será irrelevante em 2050, suspeita Harari (2018). Apesar de se desconhecer como será o futuro, sabe-se que o "atual modelo escolar" não resistirá muito tempo (NÓVOA, 2019).

Levando em conta as especificidades de uma sociedade intensiva em conhecimento, em que as transformações ocorrem com especial velocidade; sem desconsiderar a crescente heterogeneidade dos estudantes que ingressam nas universidades, seja em termos de país de origem, repertório cultural e científico, acesso às tecnologias digitais, natureza dos propósitos profissionais e dos projetos pessoais, qual seria o sentido do currículo? Em que termos é possível formular uma matriz curricular adequada, no sentido de compatível às exigências de nosso tempo? Quais seriam os critérios que balizariam as escolhas em termos dos conteúdos privilegiados e de sua distribuição ao longo dos semestres?

Cabe esclarecer que no século XXI ainda é comum o uso da expressão grade curricular, em detrimento de expressões que traduzem o conhecimento na contemporaneidade, tais como desenho, arquitetura ou matriz curricular. 0 uso da metáfora grade, de acordo com Nilson Machado (2008, p.14-15), associa a imagem do conhecimento a encadeamento, ou do conhecer como encadear. Essa visão encontra amparo nas ideias de Descartes, frente à complexidade dos fenômenos estudados, ele defendia a necessidade de subdividir a tarefa, decompô-la em partes suficientemente pequenas para serem apreendidas, e na sequência enumerar tais fragmentos, reconstruindo o objeto por meio de um encadeamento lógico linear. Isso explica a defesa de pré-requisitos e seriação no ambiente educacional. Machado (2008) esclarece que qualquer narrativa pressupõe um encadeamento; no entanto, as pressuposições cartesianas exacerbam tal necessidade.

De todo modo, não seria exagero afirmar que ainda hoje a forma com que algumas instituições organizam a educação reforça conhecimento como produto e o currículo como uma linha de montagem. Exceção são as instituições que concebem o currículo como uma "obra aberta" (ECO, 2005), algo vivo, em permanete processo de revisão (BÉDARD; BÉCHARD, 2009), flexível, modular, pouco afeito a visões monodisciplinares ou omnidisciplinares. Para Edgar Morin (1999, p. 50), "a missão primordial do ensino implica muito mais aprender a religar do que aprender a separar". Ou seja, propostas curriculares capazes de inspirar a construção de itinerários formativos cuja concepção reflete os interesses ou, nos termos do professor Machado (2006), os projetos dos estudantes. Visão alinhada às noções que trasitam entre os conceitos de desenho, arquitetura ou matriz curricular. 
Buscando imprimir coerência ao raciocínio em construção, sublinha-se que a ênfase da matriz curricular não está no número de disciplinas, na extensa carga horária, tampouco na quantidade de conteúdos programáticos previstos! Para favorecer a escolha dos itinerários formativos com potencial de respeitar os interesses dos estudantes e fortalecer os respectivos projetos, faz-se mister prever reduzido número de disciplinas obrigatórias, amplo e variado cardápio de disciplinas eletivas; disciplinas transversais capazes de inibir a excessiva fragmentação do conhecimento e encorajar a religação dos saberes; e amplo leque de atividades de interesse curricular. Sem desconsiderar que a extensão e profundidade do currículo oculto uma vez que ele irá variar entre a população estudantil em consonância com o grau de interesse e mobilização para a aprendizagem, por parte de cada um ${ }^{15}$.

\section{PROFESSORES EM INSTITUIÇÕES INTENSIVAS DE APRENDIZAGEM}

O professor é o principal agente de mudança na educação superior, reveladoramente nomeado de enseignant-chercheur (professor-pesquisador). A expressão utilizada por Nicole Colet (2009) reconhece o ensino e a pesquisa como responsabilidades distintas e complementares dos profissionais da aprendizagem. Contudo, sabidamente, as políticas de regulação da educação superior induzem a certo descaso a nobre função de uma instituição formadora de todas as profissões (CUNHA, 2018). Possivelmente, parte do desprestígio dos professores universitários se deve à dificuldade de superar o instrucionismo pelo fato de exercerem uma atividade profissional cada vez mais exigente não apenas em repertório, mas em habilidades e atitudes, sem a devida formação. Apesar de a universidade formar mestres e doutores, de a atividade de ensino ser a principal ocupação dos egressos dos mestrados e doutorados, grande parte de seu corpo docente naturaliza a docência! Enquanto Nathália Joaquim (2011) assegura que o professor universitário constrói a sua identidade docente inspirado na prática pedagógica dos professores com quem teve a oportunidade de estudar, Sandra R. Soares e Maria Isabel da Cunha (2010) acrescentam a experiência autodidata, as trocas com colegas de profissão e a reação dos estudantes.

Conhecidamente, as competências científicas requeridas pela atividade de pesquisa são desenvolvidas no âmbito da educação formal, particularmente com a realização de cursos de doutorado. As competências pedagógicas requeridas pela docência, por sua vez, decorrem sobretudo da educação informal, resultante de situações pouco estruturadas (COLET, 2009). Isso pode ajudar a entender o número de publicações disponíveis no mercado editorial cujo conteúdo reduz a atividade de ensino a um conjunto de prescrições. Compreensivelmente, elas são apreciadas por professores com pouco tempo para se dedicar à formação pedagógica. Não surpreende que o efeito colateral dessa solução fortaleça o instrucionismo e justifique atitudes de resistência a programas que contribuam para o desenvolvimento das múltiplas habilidades requeridas pelo ensino orientado pela aprendizagem.

Apesar de na atividade docente não haver base científica capaz de assegurar que o planejamento do ensino-aprendizagem, por mais cuidadoso que seja, garanta o alcance dos objetivos de aprendizagem; que a incerteza faz parte do processo educacional, uma vez que o alcance dos objetivos de aprendizagem depende fundamentalmente do interesse e mobilização do estudante (CUNHA, 2018), ser um profissional da aprendizagem requer competências cada vez mais variadas e exigentes. Para Andy Hargreaves (2004), a combinação entre crescente desprofissionalização, desprestígio do trabalho educativo e descrédito nos resultados alcançados contribuem para comprometer a autonomia dos professores. Nessa direção, Nóvoa (2019) assegura que a revitalização da pedagogia exige um investimento intelectual idêntico ao que se faz na ciência e na investigação, exige a construção de novas práticas, a procura de novas maneiras de ensinar, um esforço para recuperar o entusiasmo perdido do gesto educativo. Muito embora haja crescente compreensão da necessidade de formação pedagógica para um exercício mais adequado da docência universitária, "percebe-se certa desresponsabilização das instituições e das políticas públicas para com um movimento de profissionalização da docência da educação superior" (CUNHA, 2018, p. 22).

15 O currículo reflete uma construção cultural, por isso mesmo, é contaminado por ideologias e concepções defendidas por grupos dominantes. Por isso mesmo é um espaço de poder, não raro fundamenta e reproduz desigualdades culturais, sociais, raciais, de gênero, dentre outras. 0 currículo oculto, por sua vez, reflete um conjunto de atitudes, valores e comportamentos que explicitamente não integra o currículo, mas são implicitamente cultivados por meio das relações sociais, dos rituais, das práticas e da configuração espacial e temporal da instituição educacional (MELO et al., 2016). Refere-se aos processos educativos em geral e às práticas educativas em particular, desde que promovam aprendizagens imprevistas (MELO et al., 2016), mas reflete aprendizagens resultantes do interesse do estudante; assim sendo, o combustível do currículo oculto é a motivação, a mobilização, o engajamento ou o comprometimento do estudante. Isso é visível no contexto das metodologias ativas/colaborativas, e muito evidente em uma educação calcada na autonomia e na formação de autores, a exemplo de alguns programas de pós-graduação stricto sensu. 
Paradoxalmente, o exercício da docência ganha crescente complexidade porque a prática pressupõe a conciliação entre múltiplas atividades, dentro e fora do ambiente educacional. No contexto do produtivismo, além dos crescentes desafios da docência, espera-se êxito nas atividades que envolvem pesquisa e publicação; extensão e prestação de serviço; sem falar em gestão acadêmica. Inescapavelmente, a metáfora "professor bombril" traduz a hiperatividade a que esse profissional está cada vez mais submetido (ALCADIPANI, 2005). Como é possível realizar simultânea e competentemente tantas atividades?

Frente à complexidade do trabalho docente, cresce a importância do espírito colaborativo entre os membros de uma comunidade que junta aprende a ensinar e a aprender (SORDI, 2019). Reforçando essa ideia, Nóvoa (2019) afirma que uma das principais mudanças em curso é a passagem de um professor individual, que trabalha sozinho com a "sua" turma de estudantes, para um trabalho conjunto entre professores, no quadro de uma diversidade de formas de organização pedagógica. Isso reforça uma profissionalidade docente baseada na colaboração e na cooperação. Os conceitos variam - aprendizagem experiencial (KOLB, 1984) ${ }^{16}$, aprendizagem situada ${ }^{17}$ - mas o trabalho coletivo resulta da participação em comunidades de interesse, sobretudo, comunidades de prática (WENGER, 2006) ${ }^{18}$ ou da prática reflexiva (SCHÖN, $2000)^{19}$, comunidades de trabalho, comunidades profissionais. Em todas elas, a ideia de apreneder colaborativamente prevalece. A cultura que aproxima a cooperação da colaboração, na busca de formular soluções para os problemas da educação, sem recair na valorização da padronização e do desempenho típica das políticas públicas generalistas, pode ser a chave para se entender que a inteligência não é rara, singular, fixa e individual, ao contrário, é universal, múltipla, infinita e compartilhada (HARGREAVES, 2004, p. 43).

\section{ESPAÇOS DE ENSINO E APRENDIZAGEM}

A visão de conhecimento e arquitetura curricular também coloca em dúvida a construção do espaço educacional, particularmente o que tem sido tradicionalmente nomeado "sala de aula", por quê? À medida que a referência mais recorrente de sala de aula distância e hierarquiza professores e estudantes, coloca os estudantes em um mesmo plano, como se todos fossem iguais em repertório, propósitos (projetos) e mobilização para aprender; além de favorecer a exploração de recursos pedagógicos calcados em exposições temáticas, unilaterais, a construção de espaços favoráveis à aprendizagem modifica-se.

Para que a sala de aula seja reconhecida como mais um espaço de aprendizagem, há necessidade de se promover ajustes no espaço / mobiliário, de tal modo que ela reúna algumas características: seja acêntrica, flexível e modular (reconfigurável) para se adequar a diferentes propósitos e distintos usos, uma vez que refletirá as especificidades de métodos, estratégias, técnicas e ferramentas pedagógicas escolhidos pelo professor comprometido com a ampliação das condições que favoreçam a aprendizagem dos estudantes. Neste caso, o mobiliário ganha particular importância à medida que pode reforçar o caráter modular, flexível e multifuncional intrínseco às maneiras de ensinar e aprender aqui retratadas.

Sublinha-se que os espaços de aprendizagem não se restringem ao interior das instituições educacionais. Ganham não apenas múltiplos formatos, mas também ocupam distintos locais, a exemplo de salas de estudo, laboratórios, empresas, hotéis, cinemas, restaurantes, cafeterias, barzinhos, shoppings, parques, praças, entre outros. Em 2013, por exemplo, a

\footnotetext{
16 A teoria da aprendizagem experiencial confere particular importância aos conhecimentos de caráter experiencial, cuja utilidade para engendrar desenvolvimento só existe na medida em que podem ser confrontados, comparados, ampliados, revisados, enfim, refletidos junto a conhecimentos de caráter teórico. "Portanto, há que integrar conhecimento estruturado e conhecimento experiencial para construir um percurso de desenvolvimento profissional" (OLIVEIRA-FORMOSINHO, 2002, p.146, apud PIMENTEL, 2007)

17 A aprendizagem situada é uma derivação da aprendizagem experiencial. De modo geral fundamenta-se em situações extraídas do quotidiano; o conhecimento deriva da ação e pode ser transferido para situações idênticas; a aprendizagem resulta da interação social que conjuga o pensamento, a perceção, a resolução de problemas e interliga o conhecimento declaratório com o conhecimento prático; a aprendizagem não existe sem a ação pois resulta de um ambiente social complexo de atores, ações e situações (BRAZÃo, s.d.)

18 Uma comunidade de prática é concebida como um grupo de indivíduos com distintas competências (conhecimentos e habilidades), além de experiências, que participam ativamente em processos de colaboração, compartilhando conhecimentos, interesses, recursos, perspectivas, atividades e, sobretudo, práticas, para a produção de conhecimento tanto pessoal quanto coletivo (FERREIRA; SILVA, 2014).

19 A prática reflexiva corresponde às atividades intelectuais e afetivas em que os indivíduos se envolvem para explorar as suas experiências com o objetivo de concretizar uma nova compreensão (BOUD, KEOGH e WALKER, 1985, apud PEIXOTO e PEIXOTO, 2016). Ocorre à medida que os praticantes problematizam a sua prática e desenvolvem novas competências.
} 
Inglaterra inaugurou o pint of science, quatro anos depois a atividade foi promovida em diversas cidades do mundo, as cidades brasileiras não foram exceção.

\section{CONSIDERAÇÕES FINAIS}

As sociedades intensivas de conhecimento requerem instituições de educação intensivas em aprendizagem, e a repercussão disso sobre a educação em geral e sobre a educação superior em particular pressupõe outro paradigma pedagógico. Ultrapassar práticas docentes fortemente centradas no ensino, na direção de práticas orientadas para e pela aprendizagem, requer novos modos de planejar e realizar o ensino-aprendizagem, além de uma preocupação ainda mais imprescindível sobre o processo de avaliação da aprendizagem. Nas palavras de Maria Isabel de Almeida e Selma Garrido Pimenta (2014, p. 25),

trata-se, portanto, de propiciar condições formativas para que se desenvolva uma mudança de paradigma orientador desse processo, o que requer a definição de organizações curriculares baseadas em lógicas interdisciplinares, reorientação dos objetivos, revisão das estratégias de ensino-aprendizagem, dos sistemas de avaliação da aprendizagem, redesenho dos espaços de ensino-aprendizagem.

Nesse contexto, a naturalização da docência pode representar um freio no processo de transformação pedagógica que se faz necessário, mas ter expectativa de que o desenvolvimento das competências docentes estejam associadas apenas à realização do mestrado e do doutorado - como prevê a LDB (2017) - parece equivocado, quando sabidamente se trata de programas de formação orientados para a pesquisa acadêmica. Se são cada vez mais evidentes a ressignificação das responsabilidades assumidas pelo professor (educador, orientador, tutor, mediador, mentor, facilitador, instrutor, curador, designer educacional etc.) e a sua relevância no suporte ao desenvolvimento, por parte dos estudantes, das chamadas competências para o século XXI, faz-se cada vez mais premente a formulação de políticas voltadas à formação e ao contínuo aperfeiçoamento do professor universitário. Do contrário, a transformação do processo de ensino e aprendizagem estará sempre mais próxima de um voo de galinha, agravando ainda mais a distância do Brasil de seu potencial de colaborar para a formação de jovens capazes de viver os desafios contemporâneos (e futuros) que as sociedades cada vez mais globalizadas e intensivas em conhecimento lhe apresentam.

\section{REFERÊNCIAS}

ALCADIPANI, Rafael. A hiperatividade do professor bombril. Organização \& Sociedade, v. 2, n. 35, 2005. Disponível em: <https:// portalseer.ufba.br/index.php/revistaoes/article/view/10811/0>. Acesso em: jul. 2019.

ALHEIT, Peter. Aprendizagem biográfica: dentro do novo discurso da aprendizagem ao longo da vida. In: ILLERIS, Knud (org.). Teorias contemporâneas da aprendizagem. Porto Alegre, RS: Penso, 2013. p. 138-152.

ALMEIDA, Maria Isabel de; PIMENTA, Selma Garrido. Pedagogia universitária: valorizando o ensino e a docência na universidade. Revista Portuguesa de Educação, v. 2, n. 2, 2014. Disponível em: <http://www.scielo.mec.pt/pdf/rpe/ v27n2/v27n2a02.pdf>. Acesso em: jul. 2019.

BÉDARD, Denis; BÉCHARD, Jean-Pierre. Innover dans l'enseignement supérieur. Paris: Presses Universitaires de France. 2009.

BERNHEIM, Carlos Tünnermann. Noventa años de la Reforma Universitária de Córdoba (1918-2008). Buenos Aires: Clacso, 2008.

BOTTI, Sérgio Henrique de Oliveira; REGO, Sérgio. Preceptor, supervisor, tutor e mentor: quais são seus papéis? Revista Brasileira de Educação Médica, v. 32, n. 3, 2008. Disponível em: <http://www.scielo.br/pdf/rbem/v32n3/v32n3a11. pdf>. Acesso em: jul. 2019. 
BRAGANÇA, Inês Ferreira de Souza. Sobre o conceito de formação na abordagem (auto)biográfica. Educação, Porto Alegre, RS, v. 34, n. 2, p. 157-164, maio/ago. 2011. Disponível em: <http://revistaseletronicas.pucrs.br/ojs/index.php/ faced/article/viewFile/8700/6352>. Acesso em: jul. 2019.

BRAZÃO, José Carlos Gomes. Aprendizagem situada na formação inicial de professores: um estudo. Disponível em: <http://www3.uma.pt/pbrazao/art\&publ/Brazao\%20P\%202016\%20Aprendizagem\%20sit\%20na\%20form\%20 ini\%20prof.pdf>. Acesso em: jun. 2019.

CAMANHO, Roberto. Revolução industrial 4.0 e o glossário da inovação. Revista da ESPM, v. 24, n.2, 2018.

CASTELLS, Manuel. The network society: a cross-cultural perspective. Northampton: Edward Elgar, 2004.

CHARLOT, Bernard. Os jovens e o saber: perspectivas mundiais. Porto Alegre, RS: Artmed, 2001.

COLET, Nicole Rege. Relève professorale: des forces fraîches dans la mêlée. In: BÉDARD, Denis; BÉCHARD, Jean-Pierre. Innover dans l'enseignement supérieur. Paris: Presses Universitaires de France, 2009.

CORRÊA, Murilo Duarte Costa; CHAVES, João Guilherme Pereira; SOUSA, Diego Petyk de. Governar pela autonomia: universidade, inovação e capitalismo cognitivo. EccoS-Revista Científica, São Paulo, SP, n. 47, p.81-103, set./dez. 2018. Disponível em: <file:///C:/Users/mclima/Downloads/10690-56815-1-PB\%20(9).pdf>. Acesso em: jul. 2019.

CUNHA, Maria Isabel da. Docência na educação superior: a profissionalidade em construção. Educação, v. 41, n.1, p. 6-11, jan.abr. 2018. Disponível em: <file://C:/Users/mclima/Downloads/29725-127564-2-PB\%20(1).pdf>. Acesso em: ago. 2019.

CUNHA, Maria Isabel da. Habilidades e competências no século XXI. 3. ed. Porto Alegre, RS: Editora Mediações, 2012.

DEMO, Pedro. Conhecimento e aprendizagem: atualidade de Paulo Freire. In: TORRES, Carlos Alberto (compilador). Paulo Freire y la agenda de la educación latinoamericana en el siglo XXI. Buenos Aires: Clacso, 2001. Disponível em: <http://biblioteca.clacso. edu.ar/clacso/gt/20101010030536/torres.pdf>. Acesso em: jul. 2019.

DEMO, Pedro. O mais importante da educação importante. São Paulo, SP: Atlas, 2012.

DEMO, Pedro. Outro professor: alunos aprendem bem com professores que aprendem bem. Jundiaí, SP: Paco Editorial, 2011.

DEMO, Pedro. Educação hoje: "novas" tecnologias, pressões e oportunidades. São Paulo, SP: Atlas, 2009.

ECO, Umberto. Obra aberta: forma e indeterminação nas poéticas contemporâneas. São Paulo, SP: Perspectiva, 2005.

ENGESTRÖM, Yrjö. Learning by expanding: an activity-theoretical approach to developmental research. Helsinki: OrientaKonsultit, 1987.

FERREIRA, Andréia de Assis; SILVA, Bento Duarte da. Comunidade de prática on-line: uma estratégia para o desenvolvimento profissional dos professores de História. Educação em Revista, v.30, n.1, jan./mar. 2014. Disponível em: <http://www.scielo.br/scielo.php?script=sci_arttext\&pid=S0102-46982014000100003>. Acesso em: ago. 2019.

FREIRE, Paulo. Pedagogia: diálogo e conflito. São Paulo, SP: Cortez, 1985.

FREIRE, Paulo Pedagogia do oprimido. 18. ed. Rio de Janeiro, RJ: Paz e Terra, 1988. 
FREITAS, Teresa. Letramento digital e formação de professores. Belo Horizonte, MG, Educação em Revista, v. 26, n. 3, dez. 2010. Disponível em: <http://www.scielo.br/pdf/edur/v26n3/v26n3a17.pdf>. Acesso em: maio 2019.

FRIEDMANN, Georges. O trabalho em migalhas: especialização e lazeres. São Paulo, SP: Editora Perspectiva, 1972.

GAUTIER, Julien; VERGNE, Guillaume. L'école, le numérique et la société qui vient. Paris: Fayard / Mille et Une Nuit. 2012.

HARARI, Yuval Noah. 21 lições para o século 21. São Paulo, SP: Companhia das Letras, 2018.

HARGREAVES, Andy. O ensino na sociedade do conhecimento: educação na era da insegurança. Porto Alegre, RS: Art Med, 2004.

JOAQUIM, Nathália de Fátima. Desafios da formação docente: estágio docência e a prática de ensino em Administração. Dissertação (Mestrado em Administração) - Universidade Federal de Lavras, Lavras, MG, 2011.

KEATS, Derek; SCHMIDT, Philipp. The genesis and emergence of education 3.0 in higher education and its potential for Africa. Journal on the Internet, v.12, n. 3, mar. 2007. Disponível em: <https://firstmonday.org/ojs/index.php/fm/article/ view/1625/1540>. Acesso em: jul. 2019.

KOLB, David. Experiential learning. New Jersey: Prentice Hall. 1984.

LENGEL. Jim Gillis. Education 3.0: steps to better schools. New York, NY: Teachers College Press, 2013.

LÉVY, Pierre. Cyberdémocratie: essai de philosophie politique. Paris: Éditions Odile Jacob, 2002.

MACHADO, Nilson José. Educação, projetos e valores. 6. ed. São Paulo, SP: Escrituras Editora, 2006.

MACHADO, Nilson José. Imagens do conhecimento e ação docente no ensino superior. Cadernos de Pedagogia Universitária, USP, jun. 2008. Disponível em: <https://maiza.com.br/wp-content/uploads/2017/04/Imagens-do-conhecimentoNílson-José-Machado-USP.pdf>. Acesso em: maio 2019.

MELO, Fabíola Cristina et al. Quais são as vozes do currículo oculto? Evidência, v. 12, n. 12, 2016. Disponível em: <https:// www.uniaraxa.edu.br/ojs/index.php/evidencia/article/viewFile/506/485>. Acesso em: maio 2019.

MEZIROW, Jack. Visão geral sobre a aprendizagem transformadora. In: ILLERIS, Knud (org.). Teorias contemporâneas da aprendizagem. Porto Alegre, RS: Penso, 2013. p. 109-126.

MOREIRA, Marco Antonio; MASINI, Elcie F. Salzano. Aprendizagem significativa: a teoria de David Ausubel. São Paulo, SP: Centauro, 2006.

MORIN, Edgar. Introdução ao pensamento complexo. Porto Alegre, RS: Ed. Sulina, 2005.

MORIN, Edgar. Religação dos saberes: o desafio do século 21. Rio de Janeiro, RJ: Bertrand Brasil, 2004.

MORIN, Edgar. Complexidade e transdisciplinaridade. Natal, RN: Editora da UFRN, 1999.

MOTA, Ronaldo; SCOTT, David. Educando para a inovação e aprendizagem independente. Rio de Janeiro, RJ: Elsevier, 2014.

NÓVOA, António. Entre a formação e a profissão: ensaio sobre o modo como nos tornamos professores. Currículo sem Fronteira, v.19, n.1, jan./abr. 2019. Disponível em: <http://www.curriculosemfronteiras.org/vol19iss1articles/novoa.pdf>. Acesso em: ago. 2019.

PEIXOTO, Nuno Miguel dos Santos Martins; PEIXOTO, Tiago André dos Santos Martins. Prática reflexiva em estudantes de enfermagem em ensino clínico. Revista de Enfermagem Referência, v. IV, n. 11, Coimbra, Portugal, dez. 
2016. Disponível em: <http://www.scielo.mec.pt/scielo.php?script=sci_arttext\&pid=S0874-02832016000400013>. Acesso em: jul. 2019.

PENA-VEIGA, Alfredo. Universidades em redes em um mundo globalizado: sem renunciar à emancipação. In: SOUSA JR., José Geraldo de (orgs.). Da universidade necessária à universidade emancipatória. Brasília, DF: Editora UnB, 2012.

PIMENTEL, Alessandra. A teoria da aprendizagem experiencial como alicerce de estudos sobre desenvolvimento profissional. Estudos de Psicologia, v. 12, n.2, 2007. Disponível em: <http://www.scielo.br/pdf/epsic/v12n2/a08v12n2. pdf>. Acesso em: ago. 2019.

REICH, Robert B. O trabalho das nações: preparando-nos para o capitalismo do século 21. São Paulo, SP: Educator, 1995.

RIBEIRO, Renato Janini. Humanidades: um novo curso da USP. São Paulo, SP: Edusp, 2001.

ROGERS, Karl Ransom. Liberdade para aprender. Belo Horizonte, MG: Interlivros, 1971.

ROSA, Fernanda Ribeiro; DIAS, Maria Carolina Nogueira. Por um indicador de letramento digital: uma abordagem sobre competências e habilidades em TICs. Dissertação (Mestrado profissional em gestão e políticas públicas) - Escola de Administração de Empresas de São Paulo, 2012. Disponível em: <http://gvpesquisa.fgv.br/sites/gvpesquisa.fgv.br/ files/fernanda_ribeiro_rosa_maria_carolina_nogueira_dias.pdf>. Acesso em: maio 2019.

SANTOS, Boaventura de Sousa. A universidade no século XXI: para uma reforma democrática e emancipatória da universidade. São Paulo, SP: Cortez, 2010.

SCHÖN, Donald A. Educando o profissional reflexivo: um novo design para o ensino e a aprendizagem. Porto Alegre, RS: Artmed, 2000.

SEMESP. Mapa do ensino superior no Brasil - 2018. São Paulo, SP: Semesp, 2018.

SENADO FEDERAL. LDB: Lei de diretrizes e bases da educação nacional. Brasília, DF: Senado Federal, Coordenação de Edições Técnicas, 2017.

SERRES, Michel. Polegarzinha. Rio de Janeiro, RJ: Bertrand Brasil, 2013.

SILVA, Fernanda Cristina da. Gestão da evasão na EAD: modelo estatístico preditivo para os cursos de graduação a distância da Universidade Federal de Santa Catarina. Dissertação (Mestrado em Administração) - Universidade Federal de Santa Catarina, Florianópolis, SC, 2017. Disponível em <https://repositorio.ufsc.br/xmlui/handle/123456789/179913>.

SOARES, Paulo César. Contradições na pesquisa e pós-graduação no Brasil. Estudos Avançados, v. 32, n. $92,2018$. Disponível em: <http://www.scielo.br/pdf/ea/v32n92/0103-4014-ea-32-92-0289.pdf>. Acesso em: ago. 2019.

SOARES, Sandra Regina; CUNHA, Maria Isabel da. Programas de pós-graduação em educação: lugar de formação da docência universitária? Revista Brasileira de Pós-Graduação, Brasília, DF, v. 7, n. 14, dez. 2010.

SORDI, Mara Regina Lemes de. Docência no ensino superior: interpelando os sentidos e desafios dos espaços institucionais de formação. Educar em Revista, Curitiba, PR, v. 35, n. 75, maio/jun. 2019. Disponível em: <http://www.scielo.br/pdf/ er/v35n75/1984-0411-er-35-75-0135.pdf>. Acesso em: jul. 2019.

UNESCO. Hacia las sociedades del conocimiento. Ediciones Unesco, 2005.

WENGER, Etienne New ways oflearning: the role of communities of practice with Etienne Wenger. Organização\&Sociedade, Salvador, BA, v.13, n.38, p.161-164, jul./set. 2006. (Entrevista concedida a Jader C. Souza-Silva).

Artigo recebido em 27.02.2020 e aprovado em 07.03.2020. 